\title{
Trends in business processes management in the furniture industry in Bulgaria
}

\author{
Petya Slavova ${ }^{*}$ \\ ${ }^{1}$ BF Sciences, Department Industrial Business, 1000 UNWE, Bulgaria
}

\begin{abstract}
The present conditions of business environment of the modern economy makes business processes management a difficult task for Bulgarian managers. In the context of accelerated digitalization of the market, Covid-19 pandemic environment, the presence of political and social imbalances in the economy and the pressure of the global trends in the economy, the Bulgarian business are experiencing a difficult times in its development. Providing well-structured and properly running and managed business processes are major economic problems of increasing relevance for the management of the furniture sector. The main goals of this empirical study are: 1 . To track trends in the management of important furniture companies processes. 2 . To show the usefulness of software and digital tools in improving the business processes towards their management. 3. To suggest recommendations to improve management of the processes in furniture companies. The study is performed in 71 of the planned 100 furniture companies, who have returned answers to the questions in full. The sample included enterprises, members of the Branch Chamber of Woodworking and Furniture Enterprises (BCWFE). Data is analyzed as total as well as by individual groups including comparative analyses. The analysis is made between the results obtained from the individual firms in the sample along with analyzing the overall survey results. Comparative analysis is used to display the steps and tendencies characterizing the applicability of the methodology Business Process Management (BPM) to improve the management of business processes in organizations from the furniture industry.
\end{abstract}

\section{Current state of the furniture industry in Bulgaria}

The proportion of furniture production in the industrial growth of Bulgaria is smaller compared to the countries of the European Union. Nevertheless, the Bulgarian furniture industry continues its growth with smaller trend. In the sector "Manufacture of furniture" $1.8 \%$ of the bulk of industrial production in the country is produced and is created about $2.3 \%$ of the GDP in the industry.

The share of industrial production and that of turnover in the sector in 2019 increased by $7.3 \%$ and $3.2 \%$. The output of companies in the furniture industry is in totals 0.91 billion BGN. In 2019, the turnover on the foreign markets of furniture enterprises amounted to 411

\footnotetext{
* Corresponding author: petia.slavova@unwe.bg
} 
million BGN. On the internal market, the sector realized 483.6 million BGN. In 2019, there was a small increase of $1.2 \%$ in producer prices compared to the previous years [1]. Main industry activities are the production of furniture for offices, kitchens, other furniture and beddings. The sector comprise of 2747 companies, as $52.1 \%$ of them are located in the main capital districts.

In 2018, exports of companies in the industry increased by $4 \%$. The sector's partition in exports of industrial goods amounted to 2\%. After that on March of 2020 the exports stopped. The reason of that was the Covid-19 Pandemic conditions and the closure of borders worldwide and the leading countries in export activity "Manufacture of furniture" are close.

Bulgaria's furniture enterprises mainly manufacture medium-sized furniture. According to Eurostat by December 2019 Bulgarian production volume is divided into coffee and dining furniture $-32 \%$, elements for furniture - 30\%, non-upholstered furniture - $19 \%$, bedroom furniture $-15 \%$, kitchen furniture $-13 \%$ and other $-7 \%$.

The foreign direct investment (FDI) in the branch „Manufacture of wood and wooden products (except furniture) "is significantly bigger than those in the "production of furniture." For 2019 they are $89,6 \%$ of all FDI in the industry [2].

The biggest volume of FDI in 2019 belongs to the sub branch "production of veneer wood panels" which accounts overall $100 \%$ of the total volume of the investments. Overall $58 \%$ of the investments were invested in software systems and digitalization of the manufacture processes.

Bulgarian companies have low innovative culture. But in the last few years, they have had to make rapid progress in adapting and innovating. [3]. The furniture enterprises are forced by social reasons (Covid-19 Pandemic) to invest in new technologies as a key tool to enhance their competitiveness.

The export of wooden products shows a steady trend of growth over the last few years (2016 - 2019) and has an important proportion in industrial exports. Almost $43 \%$ of the production is directed to foreign markets. The branch is described by a positive trade balance.

\section{Empirical study of the problem}

The new environment of the modern economy, especially in condition of Covid-19 (20202021), makes business management an uneasy task for Bulgarian managers [4]. In the context of accelerated digitalization of the market, presence of environmental disbalances in the economy and the pressure pandemic global trends in the economy, the Bulgarian business is experiencing a difficult period in its development.

Well-structured and properly driven business processes are major economic problems of increasing the level for the management of the furniture branch.

The research of many literature sources indicates some bottlenecks related to issues on methods to improve the management of processes in the furniture production.

- Scope of the research

The research is conducted and performed in 71 of the planned 100 furniture companies, who have returned answers to the questions in full.

The analysis is made between the results obtained from the individual firms in the sample along with analyzing the overall survey results. Comparative analysis is used to display the steps and tendencies characterizing the applicability of the methodology Business Process Management (BPM) to improve the management of business processes in organizations from the furniture industry. [5].

\section{- Methods of Research}

The research incorporate phases and aims at establishing dependencies in the management of business processes at furniture companies during the period $2017-2020$. 
The instrument for obtaining primary information in the first phase of the study is standard questionnaire. The questions in it are used already by the author in other surveys and researches [6] also are adapted for other sectors in the economy.

The survey contains key questions on which a comparison is sought between the efficient and quality results of furniture enterprises operating without the help of mass digitization (in particular software products and tools) and those that have already used them (or are partially digitized their processes). The questions on which a comparison is sought are linked to the main problem areas in the management of processes of these enterprises. They cover the following significant indicators: reaction to changes in the macroeconomic conditions, effectiveness of companies, development of new processes, programs, software tools, reengineering.

The empirical research provides an opportunity for verification of the pre-formulated hypotheses for the presence of bottlenecks in the processes' management and their necessary digitization, refinement, reconstruction and strategic orientation.

\section{Results of the empirical study}

Processing of statistical information is made based on the software tools Excel and SPSS.

The main sector in which companies operate is "Production of furniture". From all of the firms that participated in the empirical study 71 responded in full to the questions in the questionnaire. This represents $71 \%$ of all companies that have been invited to this survey.

The research includes as well as large and tiny businesses. They constitute $21 \%$ of all the surveyed companies on Figure 1. In the interval with the smallest number of employed there is the biggest number of companies - $29 \%$.

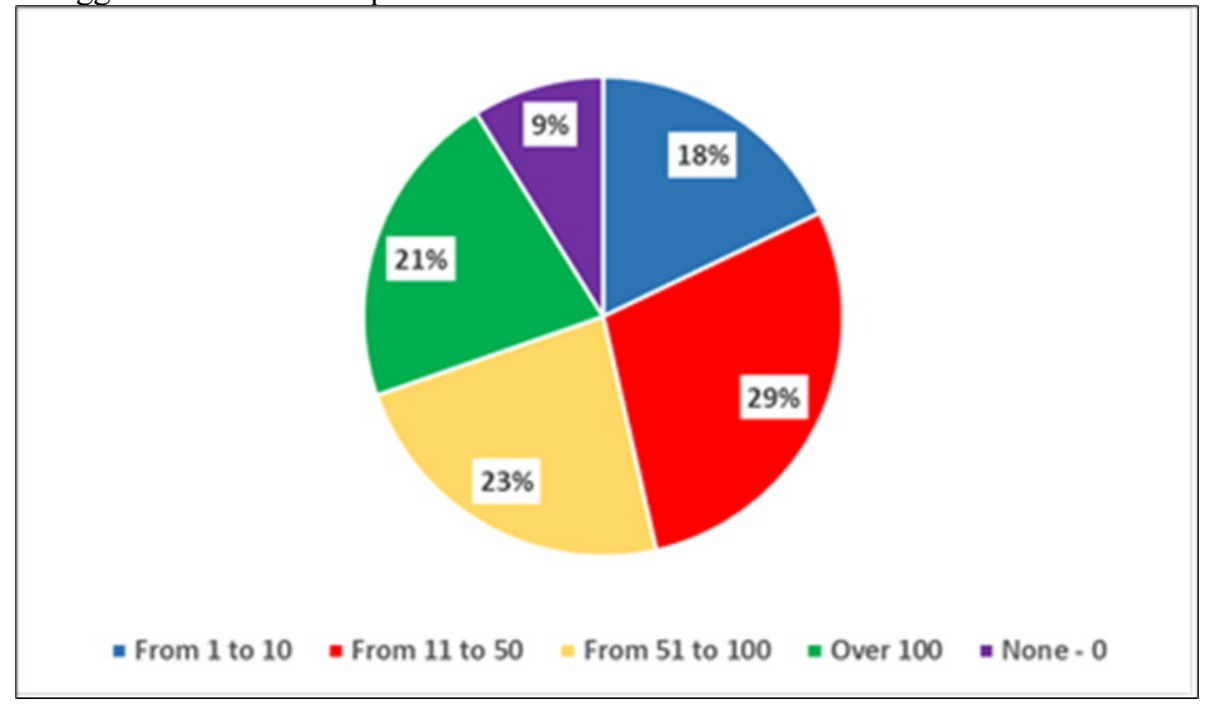

Fig. 1 Distribution of furniture companies by the number of employees

The most common answer given by the companies is "building a customer base", around $64,8 \%$. This is the most important process in the first place for their survival and should be developed. In second place, the firms indicated "sales" by $56.3 \%$, in third place they placed production by $42.3 \%$. After that processes are ranged by importance: quality management and offering additional services $-35.2 \%$; HR management and investment $21.1 \%$, etc. In the opportunity for companies to choose "other" and to fill in the desired answer, different from the possible processes mentioned, several firms have indicated a new approach to marketing and public relations (PR) and the results are presented on figure 2 . 


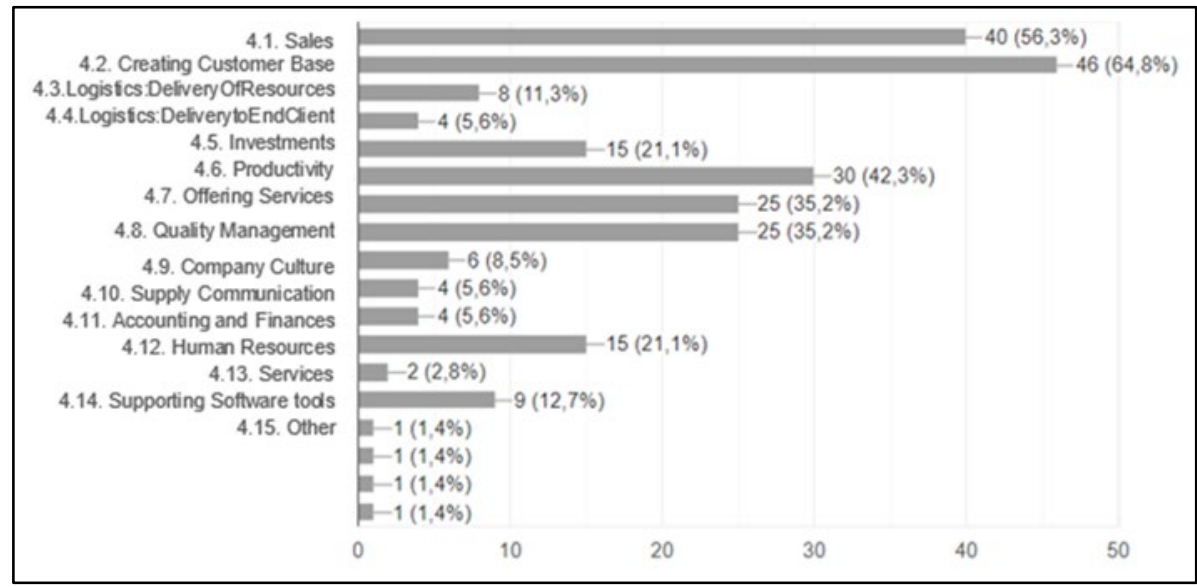

Fig. 2. Opinion of the firms on the most important processes for their development and activity

It appears that $91,5 \%$ of the companies believe that the processes they have elected needs improvement or development. Only 8, 5\% think they don't need to change any think in their processes.

The most problematic processes are: HR management process - $36.6 \%$ of the companies participating in the survey indicated this process, then in second place they highlighted the process of building a customer base $-35,2 \%$, followed by the quality management process $12 \%$ and last but not least the sales realization process - $31 \%$ which is shone on figure 3 . According to the answers, these processes listed above are most in need of improvement or refined through the necessary trend of digitalization.

Where companies do not have priority - such as maintenance and service process, delay payments, accounting and financing processes, they rarely encounter problems.

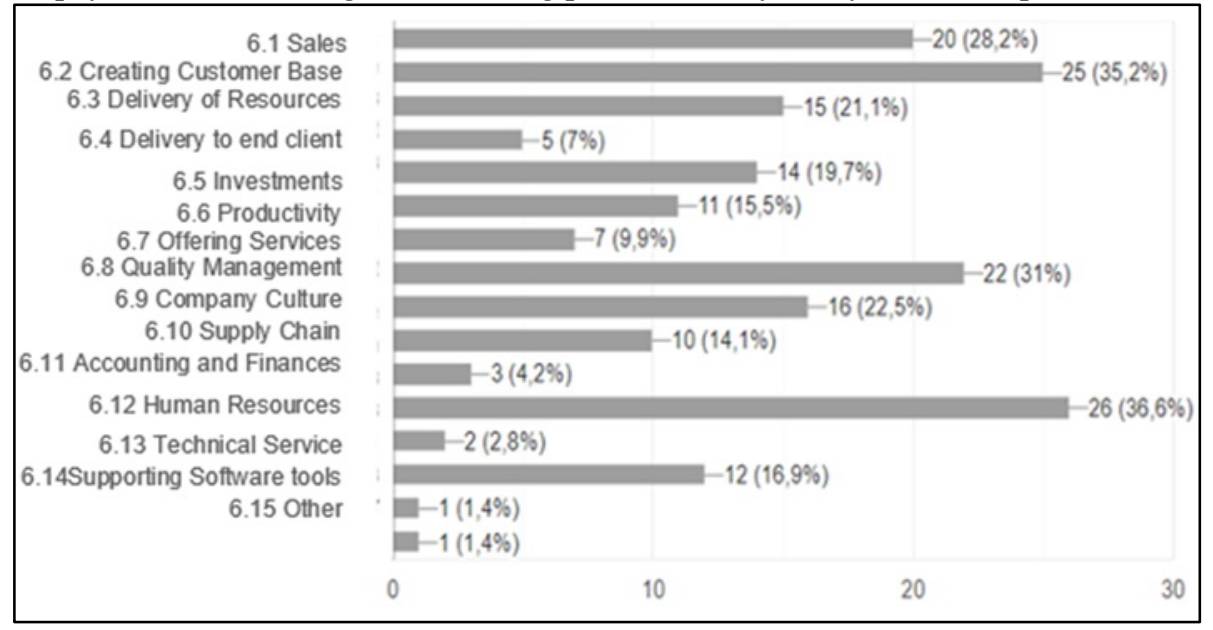

Fig. 3. Troubled processes at the companies

Almost a half of the respondents have not implemented software tools for managing business processes $-44 \%$. However, $56 \%$ on figure 4 have already employed such thus representing a main group that will reveal whether the implementation of these software tools enhance and ameliorate the management of the processes. 


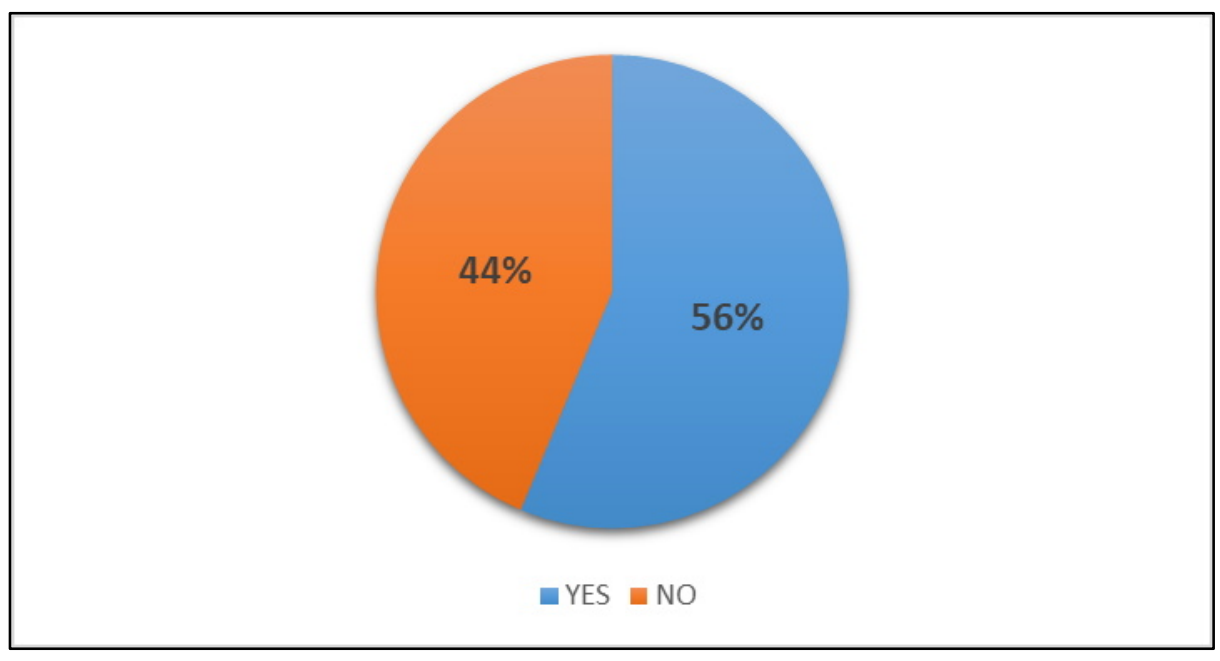

Fig. 4 Distribution of furniture enterprises with implemented and without implemented software for BPM

About $70 \%$ of enterprises believe that they have implemented comprehensive rules for the quality management of their products. Only $20 \%$ of them think they do not have detailed and comprehensive ones. This will change, because they are planning to amend management of quality processes by signing contracts with certified suppliers and introduction of quality control system- figure 5 .

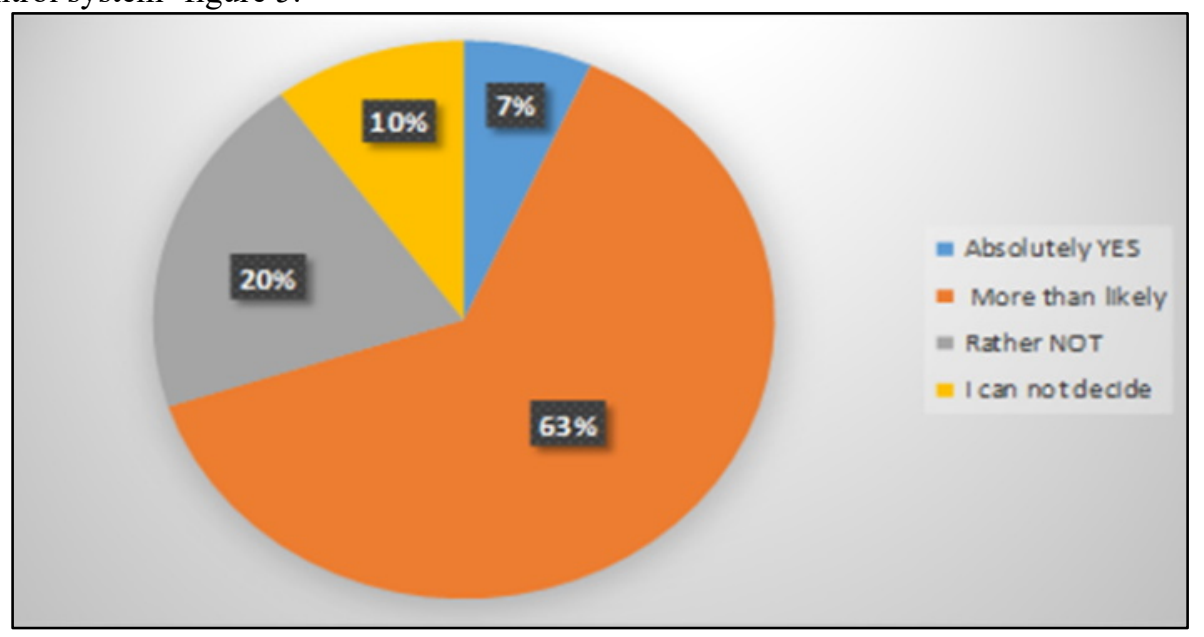

Fig.5 Distribution of enterprises on the question of whether they have implemented sufficiently comprehensive rules for quality management

The following questions cover a description of production process and the activities, approaches and methods used by managers to perfect these business process and its management. The interrogatories are formulated to eliminate the influence of external and internal factors, except on the basis of the non-introduced or already introduced software systems only.

Definitely $94 \%$ of the enterprises think that the production process has perfected with and after the introduction of business process software systems, and $6 \%$ think that it has not changed. The possible answer that the production had deteriorated was not indicated by any company. 
The most frequent reason that provoked companies to introduce business process management software was after the discovery of bottlenecks in the elements of business process management and opportunities for competitive advantages in the field of furniture production in the country. This is $62 \%$ of the furniture enterprises that took part in the research. Other reasons that firms have highlighted are that they must be part of the general policy of each company - $22 \%$ and to be innovative and trendy in the market in their branch $-15.9 \%$.

The enterprises took part in the research are categorical about the positive effect of the introduced business process software system in three areas of their activity. $45 \%$ of them think that the efficiency of all activities and processes has increased, $52 \%$ are positive that unnecessary activities have decreased, and $36 \%$ even indicate that the costs of various activities have decreased. The presented results are made within a three-year period 20172020 due to accelerated digitalization through an introduced and working software system.

After all that has been said so far, the following consequents can be made:

- Efforts are focused on using all the knowledge of the processes in order to eliminate inefficient steps and increase customer satisfaction. Therefore, more and more furniture companies in Bulgaria are turning to operating in a digital environment and adopt the approach that improving business process management should be a permanent activity;

- After the necessary digitalization and improvements of all processes: from planning and design to customer service, are interconnected in a flexible system of sequential activities;

- Software solutions provide the necessary information and assistance to assess the prerequisites for successful implementation of a project in accordance with the strategic goals of the company;

- Specialized modules of some software systems the implementations of good practices for process management in a digital environment in sole units and in company as a one body of whole;

- Attitudes are created among the top management to work in order to continuously improve important business processes.

- Prerequisites are created for clear communication between people working in the organization and the managers, in general, to new opinions and concepts to improve the functioning of activities in specific processes.

\section{Conclusion}

The study allows to make a number of summaries and to outline guidelines for future work and investigation in the field of the management of processes, their performance and mending not only in the furniture production but also in other branches of the economy.

Clearly defining the bottlenecks and demands for the growth of processes of furniture companies begins with an analysis of the firm or the unit. It stems from customer dissatisfaction, delays of payment, changes in the organization policy, the necessity for official data collection and more. Demands can be defined in different ways: top-down - arise from the manager of the firm and are related to the inclusion of strategic objective; bottomup - arise from the operational (auxiliary) processes, software tools or people who work in the organization and interact with customers; from the exterior environment - refer to conditions in the social environment (the Covid-19 pandemic and the necessary digitalization), marketing research, factors of the economy.

The BPM systems in the furniture companies in Bulgaria are of urgent and growing interest for the company management. There is an awareness of their importance and function in the pursuit of enriching the labor potential and the management tools of firms.

As a result of the empirical study of furniture organizations, the presence of: untapped potential for perfecting the business processes management is actually established; the ability 
to deal with and reduce the influence of factors in order to perfect the management of the entire company. The research also reveals the state, different results and bottlenecks in the main steps carried out in a process, but also shows that the considered software systems already take place in the priorities of organization's policy and culture, and perfecting of management becomes the responsibility of every one who works in the organization.

\section{References}

1. Ministry of Economics, Sektor "Proizvodstvo na mebeli (C31)", https://www.mi.government.bg/bg/themes/manufacture-of-furniture-31-530-276.html

2. NSI, Okonchatelni danni: "Iznos, vnos i targovsko saldo na Bulgaria po sektori na standartnata vanshnotargovska klasifikatsiya (sitc, rev. 4) prez 2017 i 2020 godina”

3. I. Georgiev, D. Blagoev, Ts. Tsvetkov Menidzhmant na firmenite inovatsii i investitsii, (Universtetsko izdatelstvo - UNSS, 2013)

4. J. Jeston, J. Nelis, Business Process Management Practical Guidelines to Successful Implementations, Third Edition, (Oxford, Elsevier Ltd., 2014)

5. B. Atanasov, R. Nikolaev, R. Miryanov Kolichestveni metodi v upravlenieto, (Nauka i ikonomika, Ikonomicheski Universitet - Varna, Bulgaria, 2012)

6. P. Slavova, Disertatcionen trud: Usyvyrshenstvane upravlenieto na biznes procesite po primera na mebelnite firmi.v Bulgaria, (UNWE, Sofia, 2016) 